\title{
Assessment of Discharge Planning Process and Quality of Care in the Emergency Department of Tamale Teaching Hospital
}

\author{
Iddrisu Mohammed, \\ Ghana Health Service, Ghana \\ Dr. Oppong Kwaku Chris, \\ Komfo Anokye Teaching Hospital, Ghana \\ John Ndebugri Alem, \\ Catholic University, Ghana \\ Norman Linda, \\ University of Ghana, Ghana
}

Doi:10.19044/esj.2020.v16n15p57 URL:http://dx.doi.org/10.19044/esj.2020.v16n15p57

\begin{abstract}
Discharge planning is the transition of patient care from the hospital setting to home, primary care provider or the community and effective discharge planning is crucial in enhancing patient recovery as it is an integral part of patient care. Poor implementation of discharge planning is associated with varying consequences for both the individual patient/family and the health system as a whole. Again, there is the challenge of the general public's perception of a dwindling standard of care by nurses and the general lowering of standards in Ghana. This study, therefore, sought to assess the discharge planning process and quality of care in the Emergency Department (ED) of Tamale Teaching Hospital (TTH). With a cross-sectional study design, 370 discharged patients were selected from the emergency department using a consecutive sampling technique. The Statistical Package for Social Sciences (SPSS), was used to analyse the data. Descriptive results took the form of frequencies, percentage distribution, means and, standard deviations and presented in tables and figures. A bivariate Pearson correlation analysis was also done to establish the relationship between structure, discharge planning and quality of care. The findings from the study revealed a good practice of the discharge planning process $(26.46, \mathrm{SD}=3.41)$ and high quality of care $(57.26, \mathrm{SD}=8.30)$. There was also a statistically significant positive relationship between discharge planning and quality of care and the same was established between the structure of the ED and quality of care. These findings imply a good implementation of the discharge planning process and
\end{abstract}


demonstrate that the public outcry about the poor quality of nursing care in Ghana is a mere perception but not a reality. There is, therefore, the need for a sensitization programme to educate the general public on what constitutes the quality of care in our healthcare delivery system.

Keywords: Discharge, Planning, Quality, Care, Patient, Carer, Emergency

\section{Introduction}

The concept of discharge planning is a key component of healthcare delivery and borders on the quality of care patients receive. Discharge planning is an interdisciplinary approach to continuity of care and involves a process that includes identification, assessment, goal setting, planning, implementation, coordination, and evaluation (Lin, Cheng, Shih, Chu, \& Tjung, 2012). According to Wells, LeClerc, Craig, Martin, and Marshall (2016), it is the quality link between hospitals, community-based services, nongovernment organisations, and caregivers. As one of the several methods of implementing transitional care, discharge planning has been identified as the most effective means of transmitting care from the hospital to patients' new location, thus achieving continuity of care to meet patient health care needs (Nordmark, Zingmark, \& Lindberg, 2016; Wallace, Smith, Fahey, \& Roland, 2016).

Globally, discharge practice has gained much attention as available literature suggests that more than one in five patients discharged experienced an adverse outcome related to their medical care (Forster et al., 2004) (Forster, Clark, Menard, Dupuis, Chernish, Chandok, Khan and Walraven. 2004). Gholizadeh, Delgoshaei, Gorji, Torani, and Janati (2016) posits that discharge planning does not only improve the quality of life in patients but also their families, hence the need for family involvement in the discharge planning process.

Despite this evidence, a review of the literature indicates that most hospitals often discharge patients with insufficient planning, poor instruction, inadequate information, lack of coordination among members of the healthcare team, and poor communication between the hospital and community (Gonçalves-Bradley, Lannin, Clemson, Cameron, \& Shepperd, 2016). A survey conducted in eleven countries of patients with complex care needs found that a good percentage of the patients in Australia, Canada, France, Germany, the Netherlands, New Zealand, Norway, Sweden, Switzerland, the United Kingdom, and the United States reported gaps in discharge planning (Schoen, Osborn, Squires, Doty, Pierson, \& Applebaum, 2011). Among the gaps included no clear medication instructions to patients and $26 \%$ of patients in the UK; and more than half of patients from the other countries indicated this gap. 
Africa is experiencing a critical shortage of health care workers, with the current number insufficient to meet population health needs with average nursing and midwifery personnel-to-population ratio of 11 per 10,000 and even less in Ethiopia and Tanzania: 2-10,000 (Brysiewicz, 2011; Wolf et al., 2012). It is therefore not uncommon to see Registered General Nurses (RGNs) who have minimal skill in emergency nursing put in the emergency department to care for patients. The lack of emergency nurses and inadequate hospital beds coupled with the burden of a high rate of road traffic accidents in Ghana (Coleman, 2014), poses a potential risk of compromising the quality of care in the system.

In Ghana, discharge planning is a feature of the healthcare system, thus every in-patient is expected to transition care through the discharge planning process. However, the real picture in an ED is that, in general, nurses who are ill-equipped with emergency nursing skills work in the department because the emergency nursing specialization is fairly new in the country. According to the Nursing and Midwifery Council's (N\&MC) of Ghana, discharge planning is a basic care for implementation by every professional nurse and is a key component of the standard procedure manual. Hence, the Ghana Health Service (GHS) standards of care require every inpatient to be given a comprehensive discharge planning through admission to discharge as detailed in the component task for nurses (Nursing and Midwifery Council of Ghana, 2015). However, it was estimated that $24 \%$ of inpatients in Margaret Marquart Catholic Hospital (MMCH) did not receive comprehensive discharge planning implementation in 2015 (Azari, 2017). This indicates that staff did not comply with the standard discharge planning implementation. In other hospitals, some patients are usually discharged without having an adequate understanding of their medications, and others not well prepared to continue self-care at home as well.

Poor implementation of discharge planning is associated with varying consequences for both the individual patient/family and the health system as a whole (Waring, Marshall, Bishop, Sahota, Walker, Currie, Fisher, \& Avery, 2014). At the individual level, it is associated with adverse events, poor compliance to treatment, complications, and readmissions (Forster, Murff, Peterson, Gandhi, \& Bates, 2003; Fox, Persaud, Maimets, Brooks, O’Brien, \& Tregunno, 2013). At the system level, poor discharge practice is associated with increased service utilization and cost of care (Greenwald, Denham, \& Jack, 2007; Snow, Beck, Budnitz, Miller, Potter, Wears, Weiss, \& Williams, 2009; Waring et al., 2014; Kansagara, Chiovaro, Kagen, Jencks, Rhyne, O'Neil, Kondo, Relevo, Motu'apuaka, \& Freeman, 2015).

Lingle (2013), indicated that evidence-based guidelines for discharge instructions, when effectively carried out, reduce readmission rates in patients, leading to better quality of life and cost-saving in North Carolina. He further 
noted that failure to provide complete discharge instructions results in nonadherence to treatment regimens and a lack of essential follow-up; the most commonly identified reasons for readmissions. Additionally, Over $28 \%$ of 684 patients experienced post-discharge adverse events (AEs), most of which were either preventable or ameliorable ( Tsilimingras, Schnipper, Duke, Agens, Quintero, Bellamy, Bates, 2015).

Despite the known benefits of comprehensive discharge planning to inpatients, the level of implementation of the discharge planning process in Ghanaian hospitals is not clearly stated. Again, there is the challenge of the general public's perception of a dwindling standard of care by nurses and the general lowering of standards in Ghana (Asamani, Kwafo, \& Ansah-Ofei, 2013). A comprehensive review of literature also reveals that almost all the adverse medical events are in one way or another associated with poor implementation of the discharged planning process (Forster et al., 2003; Tsilimingras et al., 2015). That notwithstanding, there is a paucity of literature about the implementation of the discharge planning process in the healthcare system in Ghana. Besides, there is no policy-driven framework for discharge planning practices; and no policy entity dictating discharge planning as a separate element of service package for patients as treatment and a transitional care intervention as it is in some countries (Azari, 2017). This made it imperative to study patients' perspectives about the discharge planning process and quality of care at the Emergency Department (ED) of the Tamale Teaching Hospital (TTH)

Donabedian's structure, process and outcome theory for service quality evaluation underpins the conceptual framework in this study. The concept of Healthcare quality was defined by Donabedian in his model: he described the quality assessment as a triad of structure, process, and outcome (SPO) constructs. This model was universally accepted and has been widely used in the literature especially for the development of quality standards (Ibn El-Haj, Lamrini, \& Rais, 2013).

\section{Donabedian Model of Healthcare Quality}

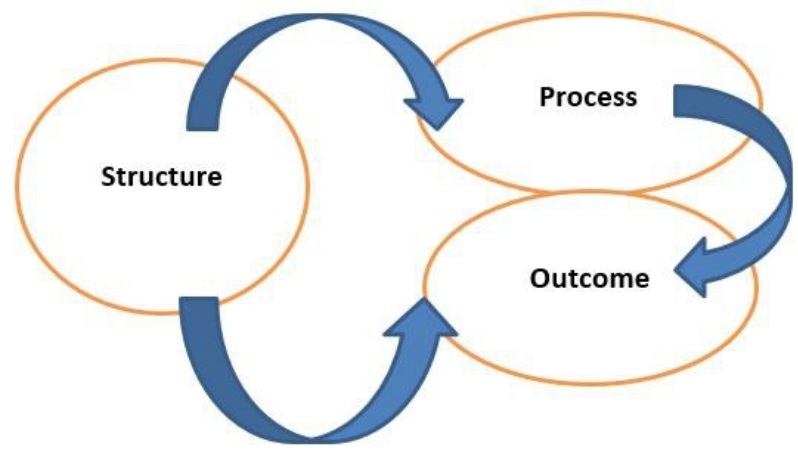


This study assessed the structure of the Emergency Department and its relationship with the quality of care in the Tamale Teaching Hospital. This will help improve the quality of care patients receive through improvement in the structure of the emergency department.

\section{Study Design and Methods}

Fetters, Curry, and Creswell (2013) describe a research design as a plan that describes how, when and where data are to be collected and analysed. The research design begins with a problem, or question, and in the context of the logic of the research, determines what kind of evidence will address the research question adequately (Hancock \& Algozzine, 2016). The study is quantitative in nature; hence a cross-sectional survey design was adopted to collect data from patients at the emergency departments of TTH. A crosssectional design was used in this study because all data were collected at one time and from a section of the population. Cross-sectional studies examine the relationship between variables of interest as they exist in a defined population at a certain point in time (Bell \& Jones, 2015).

In this study, a structured questionnaire was used to collect data from patients who meet the inclusion criteria. The questionnaire in this study consists of four sections. Section A collected data on respondents' sociodemographic characteristics such as age, gender, religious affiliation, and ethnicity. Section B contained questions about the structure of the emergency department. Section $\mathrm{C}$ dealt with the discharge planning process and the last section (D) contained questions on the quality of care in four domains (responsiveness, individualisation, knowledge, and coordination.

Permission was sought and obtained from management and the research unit in particular of TTH with an introductory letter from the Ghana College of Nurses and Midwives. Once permission was granted, the purpose of the study was explained in simple language to the understanding of the patients who met the inclusion criteria. If respondents agreed to participate in the study, they were required to sign or thumbprint a consent form to which they reserve the right to decline participation or withdraw from the study at any point in time they wish to do so. After obtaining the consent of respondents, face-face interview with the written questionnaire was the main method of data collection. Three research assistants were trained to assist the researcher in data collection. English and Dagbani were the main languages used in data collection. However, for those who could not understand any of these languages, the services of an interpreter were sought and the questionnaire filled appropriately. 


\section{Data Management and Analysis}

The Statistical Package for Social Sciences (SPSS), now known as Predictive Analytics Software (PASW) version 20 was used to analyse the data. Filled-in questionnaires were checked for completeness, coded and entered directly into the software for analysis. Data cleaning was done after data entry by running frequencies and checking for out of range responses and missing values. Both descriptive and inferential statistical analyses were carried out to meet the study objectives. Descriptive results took the form of frequencies, percentage distribution, means, and standard deviations and presented in tables. Moreover, with a $\mathrm{p}$-value of less than or equal to 0.05 ( $\mathrm{p} \geq$ 0.05 ) as the significance level at a $95 \%$ confidence level, a bivariate correlation analysis was done to establish the relationship between structure, discharge planning and quality of care. Since the dependent variable (quality of care) is assumed to be measured on the interval scale, Pearson Product Moment Correlation (Pearson r) was used to establish the relationships.

To ensure validity, the researcher conducted an extensive literature review and thoroughly examined the adapted questionnaire to ensure that all the variables to be measured are included; questions that were irrelevant to the current study were removed and other questions modified to meet the study objectives. Additionally, pre-test of the study instrument, the questionnaire was conducted in the Navrongo Municipality with twenty (20) patients who met the inclusion criteria. This exercise was to validate the questionnaire, whether it is too long or short, difficult wordings or contain culturally sensitive questions. In ensuring reliability, the reliability coefficient (Cronbach's alpha) was calculated after the pre-test of the questionnaire to ensure internal consistency. The Cronbach's alpha for the structure was (0.75) that of the discharge planning was (0.86) and the quality of care was (0.77).

Ethical considerations are very important aspects of the research process. The ethical principles underlying research are general and concern issues such as privacy, anonymity, confidentiality, honesty, and respect for fundamental human rights (W. Creswell, 2009). The principle of anonymity and confidentiality was adhered to, hence, the identity of participants was not a requirement on the questionnaire and the information obtained was strictly confidential.

The proposal for this study was submitted to the Tamale Teaching Hospital (TTH) Ethics Review Committee for approval before the start of the study. Also, a letter of certification from the Ethical Committee of the Ghana College of Nurses and Midwives together with a letter of permission was added to the proposal and submitted to the institutional Review Board (IRB) of TTH.

This study involved patients and or caregivers as the participants who were admitted into the emergency department and discharged home. Only 
discharged patients and or caregivers who were ready to leave the hospital and consented to participate in this study were approached. Patients and or caregivers who could not communicate verbally or in writing in languages the researcher/assistants understand were excluded.

Participants involved in this study were exposed to the risk of psychological harm because some of the questions that were asked for the data collection may evoke painful memories. Participants, however, may benefit, in the long term, in the form of health gains and satisfaction from clinical services if the findings from this study are used for the improvement of clinical practices.

Privacy for all participants was ensured by collecting data at a convenient setting such that only one participant was interviewed at a time. For patient-participants in particular, data was collected in a setting outside each ward to enable them to feel more secure in giving responses. Moreover, completed questionnaires were collected into opaque envelopes provided to ensure confidentiality. Ultimately completed questionnaires were kept under lock and key at the end each day to ensure the data was safe from unauthorized access. Some authors consider the right to privacy to be within the justice principle (Polit \& Beck, 2008:174).

Patients and or caregivers who accepted to participate in this study were asked to sign a consent form indicating their voluntary agreement to participate in the study. Before a participant signed the consent form, they were required to read the full information sheet or have it explained to them in a language they best understood.

It was explained, before the start of data collection, to every participant that participation and consenting in this study was voluntary and that they could withdraw any time in the interview and data collected before their withdrawal will be destroyed. Participants were also informed that withdrawing the study will not attract any denial of benefits.

\section{Findings}

\section{Structure Of The Emergency Department (Ed)}

In this study, structure refers to prerequisites, such as hospital buildings, staff, and equipment in the facility. Because the study was conducted in one department, the assessment of the structure was about the emergency department. Appendix A presents the profile of staff and equipment available in the department. On the other hand, the appearance of the department was assessed with five items and the findings presented in table 4.6 below. From the results presented in the table below, the high mean score on the total score on structure (appearance), 13.32 ( $\mathrm{SD}=2.83$ ) suggests a high standard emergency department. In terms of adequacy of space in the department, $62.4 \%(n=231)$ and $6.5 \%(n=24)$ of respondents rated good and poor 
respectively. Additionally, the majority of the respondents, $60.8 \%(\mathrm{n}=225)$ rated the cleanliness of the department as good whereas only $4.3 \%(n=16)$ gave a poor rating to the cleanliness of the department.

Table 1. Structure of the Emergency Department

\begin{tabular}{|c|c|c|c|c|c|c|c|}
\hline Items & $\mathbf{N}$ & Poor & Fair & Good & Excellent & Mean & SD \\
\hline $\begin{array}{c}\text { Adequacy of space in } \\
\text { the ward }\end{array}$ & 370 & $24(6.5)$ & $52(14.1)$ & $231(62.4)$ & $63(17.0)$ & 2.90 & .74 \\
\hline $\begin{array}{l}\text { Cleanliness of the } \\
\text { ward }\end{array}$ & 370 & $16(4.3)$ & $68(18.4)$ & $225(60.8)$ & $61(16.5)$ & 2.89 & .71 \\
\hline $\begin{array}{l}\text { Accessibility of } \\
\text { washrooms }\end{array}$ & 370 & $42(11.4)$ & $113(30.5)$ & $163(44.1)$ & $52(14.1)$ & 2.60 & .86 \\
\hline $\begin{array}{l}\text { Cleanliness of the } \\
\text { washrooms }\end{array}$ & 370 & $44(11.9)$ & 137 (37) & $150(40.5)$ & $39(10.5)$ & 2.49 & .83 \\
\hline $\begin{array}{l}\text { Availability of } \\
\text { privacy in the ward }\end{array}$ & 370 & $45(12.2)$ & $149(40.3)$ & $151(40.8)$ & $25(6.8)$ & 2.42 & .78 \\
\hline Total Structure & 370 & & & & & 13.32 & 2.83 \\
\hline
\end{tabular}

Source: Field data 2018

\section{Relationship between Structure of the Emergency Department and Quality of Care}

To establish the relationship between structure and quality of care, a Pearson product-moment correlation (Pearson r) analysis was done as the variables were assumed to be linearly related and measured on an interval scale. The results showed a statistically significant positive correlation between the structure of the ED and all the domains of quality of care. There was a statistically significant positive correlation between structure and responsiveness $(\mathrm{r}=.528, \mathrm{p}=.001)$. This is a moderate correlation and implies that when the score on structure increases, there is a corresponding increase in the total score on responsiveness. Similarly, there was a statistically significant positive correlation between structure and individualisation $(\mathrm{r}=.417, \mathrm{p}=$ $.001)$, knowledge $(\mathrm{r}=.396, \mathrm{p}=.001)$ and coordination $(\mathrm{r}=.300, \mathrm{r}=.001)$. The results are presented in Table 1 below.

Table 2 Relationship between Structure and Quality of Care.

\begin{tabular}{ccc}
\hline Quality of care & \multicolumn{2}{c}{ Structure of the ED } \\
Responsiveness & $.528^{* *}$ & $\mathrm{p}$-value (2-tailed) \\
\hline Individualisation & $.417^{* *}$ & $\mathbf{. 0 0 1}$ \\
Knowledge & $.396^{* *}$ & .001 \\
Coordination & $.300^{* *}$ & .001 \\
\hline
\end{tabular}

Dependent variable: Quality of care, $95 \%$ confidence level $(\alpha=.05)$ 


\section{Discussion}

The purpose of the study was to quantitatively evaluate the discharge planning process and quality of care patients and caregivers received in the ED of the Tamale Teaching Hospital. The quality of bedside nursing care is constantly affected by the related hospital services such as the quality of beds, the quality, and cleanliness of bed linens, the number of bathrooms available, the quality of the bathrooms available, cleanliness of the toilets, and ventilation and lighting in the wards (Al-Hussami, Al-Momani, Hammad, Maharmeh, \& Darawad, 2017). From the findings in the current study, the high mean score on the total score on structure (appearance), suggests a high standard emergency department. On the contrary, Bahrami, Maghsoudi, Rafiee, Alfaraj, and Ghasemi (2014) found that there was maximum satisfaction related to support nursing services and minimum satisfaction was related to the structure of the ward.

In terms of adequacy of space in the department, $62.4 \%$ and $6.5 \%$ of respondents rated good and poor respectively. Contradicting the findings in the current study, descriptions by the participants in a qualitative Irish study portrayed an ED that was overcrowded, dirty, lacking in resources and resembling a disaster zone or hospital scene (Coughlan \& Corry, 2007). Eitel, Rudkin, Malvehy, Killeen, \& Pines (2010) study indicated that overcrowding in emergency departments (EDs) is a concerning global problem and has been identified as a national crisis in some countries.

Additionally, the majority of the respondents $60.8 \%$ rated the cleanliness of the emergency department in the current study as good whereas only $4.3 \%$ gave a poor rating to the cleanliness of the department. Similarly, Rajkumari and Nula (2017) found that the majority of respondents $(77.5 \%)$ were averagely satisfied with the cleanliness of a government health facility in India. Again, $80.6 \%$ of respondents mentioned that they were fairly satisfied with the cleanliness of the hospital's ED in a University Teaching Hospital in Nepal (Subedi \& Uprety, 2014). Many studies have also shown that environmental cleaning is effective in reducing pathogens transmitted within the hospital. However, others argue that cleaning is not an evidence-based science because there is no scientific standard to measure the outcome of an individual cleaner or to assess the result of cleanliness (Dancer, 2009).

Furthermore, the findings from the current study showed a statistically significant positive correlation between the structure of the ED and all the domains of quality of care. This implies that an ED with a good structure has a positive impact on the quality of care and the reverse could also be true. Similar to this finding, crowding in emergency departments (EDs) nationally and worldwide has impacted the quality of care (Bernstein, Aronsky, Duseja, Epstein, Handel, Hwang, McCarthy, McConnell, Pines, \& Rathlev, 2009). Contradicting these findings, a cross-sectional study by Ghose and Adhsih 
(2011) revealed no association between cleanliness services and patient satisfaction with the quality of nursing care.

Increases in inpatient mortality, medication errors, pain, length of hospital stay, and other deleterious effects have been documented (Sprivulis, Da Silva, Jacobs, Frazer, \& Jelinek, 2006). When an ED is crowded, all beds may be occupied, and overflow patients frequently are placed in hallways to receive care. In such circumstances, emergency healthcare professionals are placed in a difficult position of providing care to patients with suboptimal nursing support and lack of privacy. Placing new patients on the floor at the ED until a bed becomes available poses a further risk, as there is no way to directly observe or monitor patients. Some hospital administrators insist that care in hallways be provided but fail to provide logistical support needed to accomplish this task. However, a long stay of patients in the ED has been long recognized as one of the prime causes of ED crowding (White, Biddinger, Chang, Grabowski, Carignan, \& Brown, 2013). Therefore, regular transfer of detained patients in the ED to other inpatient wards is safe and effective (Viccellio, Santora, Singer, Thode Jr, \& Henry, 2009).

\section{Implications for Nursing Practice and Policy}

The research results showed good discharge planning process practice and high quality of care, there is a need for more family involvement in the process. There is the need for the hospital management to demonstrate that discharge practice is a priority, with much emphasis on family involvement. This can be done through in-service training on discharge planning for all staff at the emergency department of the hospital.

The Ghana Health Service should develop a clear policy and guidelines on discharge planning and its implementation. Given that discharge planning is a service in itself, there is the need for its implementation to be designated to a specific officer. This will allow for proper implementation of the process. The Ministry of Health $(\mathrm{MOH})$ in collaboration with Ghana Health Service (GHS) should also consider a sensitization programme that would seek to educate the general public about the actual role of nurses in the healthcare delivery system. The finding about quality of care from the current study demonstrates that the public outcry about poor quality of nursing care in Ghana is a mere perception but not a reality. Hence, this sensitization programme will be very helpful in demystifying the public perception about the quality of nursing care in Ghana.

\section{Conclusion}

The findings from the study revealed a good practice of the discharge planning process and high quality of care with a greater proportion of the respondents reporting good discharge planning practices and high quality. 
These findings refute the media outcry about a dwindling quality of nursing in most healthcare facilities in northern Ghana. The worrying revelation of this study, however, was the point where just $5.9 \%$ of the respondents indicated that there was family involvement the discharge planning process. This calls for more improvement in some aspects of the discharge planning process and quality of care.

\section{Conflict of Interest Statement}

The Authors of the manuscript declare that no conflict of interest exists.

\section{Acknowledgment}

The authors thank Miss Dzigbodi Kpikpitse, the Research and Ethics Committee Chair at the Ghana College of Nurses and Midwives, West Legon Accra and all the staff of the emergency department of TTH.

\section{References:}

1. Adua, E., Frimpong, K., Li, X., \& Wang, W. (2017). Emerging issues in public health: a perspective on Ghana's healthcare expenditure, policies, and outcomes. EPMA Journal, 8(3), 197-206. DOI: https://doi.org/10.1007/s13167-017-0109-3

2. Adugbire, A. (2015). Exploration of Surgical Patients' Perspectives of Peri-Operative Nursing Care at the Regional Hospital, Bolgatanga. The University of Ghana.

3. Afzal, M., Cometto, G., Rosskam, E., \& Sheikh, M. (2011). Global Health Workforce Alliance: increasing the momentum for health workforce development. Revista Peruana de medicina experimental y Salud Publica, 28(2), 298-307. DOI: https://doi.org/10.1590/S172646342011000200018

4. Ahmad, M. M., Al-Daken, L. I. 1., \& Ahmad, H. M. (2015). Quality of life for patients in medical-surgical wards. Clinical Nursing Research, 24(4), 375-387.

5. Al-Hussami, M., Al-Momani, M., Hammad, S., Maharmeh, M., \& Darawad, M. (2017). Patients' perception of the quality of nursing care and related hospital services. DOI: 10.15761/HPC.1000110

6. Alper, E., O'Malley, T., \& Greenwald, J. (2017). Hospital discharge and readmission. UpToDate AHRQ Patient Safety Network.

7. Ameh, S., Gómez-Olivé, F. X., Kahn, K., Tollman, S. M., \& KlipsteinGrobusch, K. (2017). Relationships between structure, process, and outcome to assess the quality of integrated chronic disease management in a rural South African setting: applying a structural equation model. BMC health services research, 17(1), 229. DOI: https://doi.org/10.1186/s12913-017-2177-4 
8. Anderson, J., Malone, L., Shanahan, K., \& Manning, J. (2015). Nursing bedside clinical handover-an integrated review of issues and tools. Journal of Clinical Nursing, 24(5-6), 662-671.

9. Asamani, J. A., Kwafo, E. O., \& Ansah-Ofei, A. M. (2013). Planning among nurse managers in district hospitals in Ghana. Nursing Management-UK, 20(8).

10. Atakro, C. A., Ninnoni, J. P., Adatara, P., Gross, J., \& Agbavor, M. (2016). A qualitative inquiry into challenges experienced by registered general Nurses in the emergency department: A study of selected hospitals in the Volta region of Ghana. Emergency medicine international, 2016.

11. Azari, A. S. (2017). Assessment of Factors Affecting Discharge Planning Implementation in Margaret Marquart Catholic Hospital. The University of Ghana.

12. Bahrami, M. A., Maghsoudi, M. H., Rafiee, N., Alfaraj, R. M., \& Ghasemi, N. (2014). Evaluating the satisfaction of patients referring to the emergency ward of Shahid Sadooghi Hospital, Yazd, Iran, in 2013. International Journal of Health-System and Disaster Management, 2(3), 161.

13. Bashkin, O., Caspi, S., Haligoa, R., Mizrahi, S., \& Stalnikowicz, R. (2015). Organizational Factors affecting the length of stay in the emergency department: initial observational study. Israel Journal of health policy research, 4(1), 38. DOI: https://doi.org/10.1186/s13584015-0035-6

14. Bauer, M., Fitzgerald, L., Haesler, E., \& Manfrin, M. (2009). Hospital discharge planning for frail older people and their families. Are we delivering best practice? A review of the evidence. Journal of Clinical Nursing, 18(18), 2539-2546.

15. Bell, A., \& Jones, K. (2015). Explaining fixed effects: Random-effects modeling of time-series cross-sectional and panel data. Political Science Research and Methods, 3(1), 133-153.

16. Ben-Morderchai, B., Herman, A., Kerzman, H., \& Irony, A. (2010). Structured discharge education improves early outcome in orthopedic patients. International Journal of Orthopaedic and Trauma Nursing, 14(2), 66-74.

17. Bernstein, S. L., Aronsky, D., Duseja, R., Epstein, S., Handel, D., Hwang, U., . . . Rathlev, N. (2009). The effect of emergency department crowding on clinically oriented outcomes. Academic Emergency Medicine, 16(1), 1-10.

18. Bouaiti, E., Zidouh, S., Boufaress, A., Kessouati, J., Elkafssaoui, S., Mrabet, M., \& Belyamani, L. (2016). Understanding the factors that influence patient satisfaction with the Emergency department in 
Moroccan hospital. IOSR Journal Of Humanities And Social Science (IOSR-JHSS), 21(8), 11. DOI: DOI: 10.9790/0837-2108110109

19. Bowers, D., House, A., \& Owens, D. H. (2011). Getting started in health research: John Wiley \& Sons.

20. Bremnes, H. S., Wiig, A. K., Abeid, M., \& Darj, E. (2018). Challenges in day-to-day midwifery practice; a qualitative study from a regional referral hospital in Dar es Salaam, Tanzania. Global health action, 11(1), 1453333.

DOI: https://doi.org/10.1080/16549716.2018.1453333

21. Brysiewicz, P. (2011). Emergency nurses: an essential component of emergency care in Africa. African Journal of Emergency Medicine, 1(1), 3-4. DOI: https://doi.org/10.1016/j.afjem.2011.05.003

22. Chaboyer, W., Foster, M., Kendall, E., \& James, H. (2002). ICU nurses' perceptions of discharge planning: a preliminary study. Intensive and Critical Care Nursing, 18(2), 90-95.

23. Chang, C. H., \& Shih, S.-R. (2010). Research of patient's nursing care demand in the Emergency room. The Journal of Human Resource and Adult Learning, 6(2), 110.

24. Coleman, A. (2014). Road traffic accidents in Ghana: a public health concern, and a call for action in Ghana,(and the Sub-Region). Open Journal of Preventive Medicine, 4(11), 822. doi: https://doi.org/10.4236/ojpm.2014.411092

25. Coughlan, M., \& Corry, M. (2007). The experiences of patients and relatives/significant others of overcrowding in accident and emergency in Ireland: a qualitative descriptive study. Accident and Emergency Nursing, 15(4), 201-209.

26. Creswell, J. W. (2009). Mapping the field of mixed methods research: SAGE Publications Sage CA: Los Angeles, CA.

27. Dancer, S. J. (2009). The role of environmental cleaning in the control of hospital-acquired infection. Journal of hospital Infection, 73(4), 378-385.

28. Dinh, T. T. H., Bonner, A., Clark, R., Ramsbotham, J., \& Hines, S. (2016). The effectiveness of the teach-back method on adherence and self-management in health education for people with chronic disease: a systematic review. JBI database of systematic reviews and implementation reports, 14(1), 210-247.

29. Donabedian, A. (1988). The quality of care: how can it be assessed? Jama, 260(12), 1743-1748.

30. Donaldson, M. S. (1999). Measuring the quality of health care: a statement by the National Roundtable on Health Care Quality.

31. Dougherty, M. B., \& Larson, E. L. (2010). The nurse-nurse collaboration scale. Journal of Nursing Administration, 40(1), 17-25. 
32. Douri B., J. (2014) Workload and Nursing Care: A Case Study in Some Selected Hospitals in the Brong Ahafo Region of Ghana.

33. Drost, E. A. (2011). Validity and reliability in social science research. Education Research and Perspectives, 38(1), 105-123.

34. Dunnion, M. E., \& Kelly, B. (2007). Discharge of the older person from the emergency department-the perceptions of health professionals. International journal of older people nursing, 2(2), 102110.

35. Dzomeku, V., Ba-Etilayoo, A., Perekuu, T., \& Mantey, R. (2013). Inpatient satisfaction with nursing care: a case study at Kwame Nkrumah University of Science and Technology hospital. International Journal of Research in Medical and Health Sciences, 2(1), 19-24.

36. Eitel, D. R., Rudkin, S. E., Malvehy, M. A., Killeen, J. P., \& Pines, J. M. (2010). Improving service quality by understanding emergency department flow: a White Paper and position statement prepared for the American Academy of Emergency Medicine. The Journal of emergency medicine, 38(1), 70-79.

37. Engel, K. G., Buckley, B. A., Forth, V. E., McCarthy, D. M., Ellison, E. P., Schmidt, M. J., \& Adams, J. G. (2012). Patient understanding of emergency department discharge instructions: where are knowledge deficits greatest? Academic Emergency Medicine, 19(9), E1035E1044. doi: https://doi.org/10.1111/j.1553-2712.2012.01425.x

38. Eygelaar, J. E., \& Stellenberg, E. L. (2012). Barriers to quality patient care in rural district hospitals. curationis, 35(1), 1-8.

39. Fetters, M. D., Curry, L. A., \& Creswell, J. W. (2013). Achieving integration in mixed methods designs - principles and practices. Health services research, 48(6pt2), 2134-2156.

40. Forster, A. J., Clark, H. D., Menard, A., Dupuis, N., Chernish, R., Chandok, N., Khan, A., Walraven, C. (2004) Adverse events among medical patients after discharge from hospital. CMAJ. 2004;170:345349

41. Forster, A. J., Murff, H. J., Peterson, J. F., Gandhi, T. K., \& Bates, D. W. (2003). The incidence and severity of adverse events affecting patients after discharge from the hospital. Annals of internal medicine, 138(3), 161-167.

42. Fox, M. T., Persaud, M., Maimets, I., Brooks, D., O’Brien, K., \& Tregunno, D. (2013). Effectiveness of early discharge planning in acutely ill or injured hospitalized older adults: a systematic review and meta-analysis. BMC geriatrics, 13(1), 70.

43. Freitas, J. S. d., Silva, A. E. B. d. C., Minamisava, R., Bezerra, A. L. Q., \& Sousa, M. R. G. d. (2014). Quality of nursing care and 
satisfaction of patients attended at a teaching hospital. Revista latinoamericana de enfermagem, 22(3), 454-460.

44. Ghaffari, F., Jahani Shourab, N., Jafarnejad, F., \& Esmaily, H. (2014). Application of Donabedian quality-of-care framework to assess the outcomes of preconception care in urban health centers, Mashhad, Iran in 2012. Journal of Midwifery and Reproductive Health, 2(1), 50-59.

45. Gholizadeh, M., Delgoshaei, B., Gorji, H. A., Torani, S., \& Janati, A. (2016). Challenges in patient discharge planning in the health system of Iran: A qualitative study. Global journal of health science, 8(6), 168. doi: https://doi.org/10.5539/gjhs.v8n6p168

46. Ghose, A., \& Adhsih, V. (2011). Patient satisfaction with medical services: Hospital-based study. Health Popul, 34(4), 232-242.

47. Gittell, J. H., Weinberg, D., Pfefferle, S., \& Bishop, C. (2008). Impact of relational coordination on job satisfaction and quality outcomes: a study of nursing homes. Human Resource Management Journal, 18(2), 154- 170 .

48. Gonçalves-Bradley, D. C., Lannin, N. A., Clemson, L. M., Cameron, I. D., \& Shepperd, S. (2016). Discharge planning from hospital. Cochrane database of systematic reviews(1).

49. Gondwe, W. T., \& Brysiewicz, P. (2008). Emergency nursing experience in Malawi. International emergency nursing, 16(1), 59-64.

50. Goodman, H. (2010). Discharge from hospital: The importance of planning. British Journal of Cardiac Nursing, 5(6), 274-279.

51. Greenwald, J. L., Denham, C. R., \& Jack, B. W. (2007). The hospital discharge: a review of a high risk care transition with highlights of a reengineered discharge process. Journal of Patient Safety, 3(2), 97106.

52. Greenwood, D. J., \& Levin, M. (2006). Introduction to action research: Social research for social change: SAGE publications.

53. Han, C.-Y., Barnard, A., \& Chapman, H. (2009). Discharge planning in the emergency department: a comprehensive approach. Journal of Emergency Nursing, 35(6), 525-527. doi: https://doi.org/10.1016/j.jen.2009.01.015

54. Hancock, D. R., \& Algozzine, B. (2016). Doing case study research: A practical guide for beginning researchers: Teachers College Press.

55. Hankey, G. (2017). Patient flow management in a South African academic hospital: the Groote Schuur Hospital (GSH) case. Stellenbosch: Stellenbosch University.

56. Havens, D. S., Vasey, J., Gittell, J. H., \& LIN, W. T. (2010). Relational coordination among nurses and other providers: impact on the quality of patient care. Journal of nursing management, 18(8), 926-937. 
57. He, J., Gallego, B., Stubbs, C., Scott, A., Dawson, S., Forrest, K., \& Kennedy, C. (2018). Improving patient flow and satisfaction: An evidence-based pre-admission clinic and transfer of care pathway for elective surgery patients. Collegian, 25(2), 149-156.

58. Heale, R., \& Twycross, A. (2015). Validity and reliability in quantitative studies. Evidence-based nursing, ebnurs-2015-102129.

59. Henoch, I., Lövgren, M., Wilde-Larsson, B., \& Tishelman, C. (2012). Perception of quality of care: comparison of the views of patients' with lung cancer and their family members. Journal of Clinical Nursing, 21(3-4), 585-594.

60. Hesselink, G., Zegers, M., Vernooij-Dassen, M., Barach, P., Kalkman, C., Flink, M., . . . Orrego, C. (2014). Improving patient discharge and reducing hospital readmissions by using Intervention Mapping. BMC health services research, 14(1), 389.

61. Ibn El Haj, H., Lamrini, M., \& Rais, N. (2013). Quality of care between Donabedian model and ISO9001V2008. International Journal for Quality Research, 7(1).

62. Jack, B. W., Chetty, V. K., Anthony, D., Greenwald, J. L., Sanchez, G. M., Johnson, A. E., . . . Manasseh, C. (2009). A reengineered hospital discharge program to decrease rehospitalization: a randomized trial. Annals of internal medicine, 150(3), 178-187. doi: https://doi.org/10.7326/0003-4819-150-3-200902030-00007

63. Jardien-Baboo, S., van Rooyen, D., Ricks, E., \& Jordan, P. (2016). Perceptions of patient-centred care at public hospitals in Nelson Mandela Bay. health sa gesondheid, 21(1), 397-405. doi: https://doi.org/10.1016/j.hsag.2016.05.002

64. Javadi, M., Karimi, S., Raiesi, A., Yaghoubi, M., \& Kaveh, K. (2011). Comparison of patients' and nurses' viewpoints about responsiveness among a sample from public and private hospitals of Isfahan. Iranian journal of nursing and midwifery research, 16(4), 273.

65. Jiang, H. J., Boutwell, A. E., Maxwell, J., Bourgoin, A., Regenstein, M., \& Andres, E. (2016). Understanding patient, provider, and system factors related to Medicaid readmissions. The Joint Commission Journal on Quality and Patient Safety, 42(3), 115-121.

66. Johnson, S. L. (2009). International perspectives on workplace bullying among nurses: a review. International nursing review, 56(1), 34-40.

67. Juran, J. M. (1986). The quality trilogy. Quality progress, 19(8), 1924.

68. Kaissi, A., Johnson, T., \& Kirschbaum, M. S. (2003). Measuring teamwork and patient safety attitudes of high-risk areas. Nursing Economics, 21(5), 211. 
69. Kansagara, D., Chiovaro, J., Kagen, D., Jencks, S., Rhyne, K., O'Neil, M., . . . Freeman, M. (2015). Transitions of care from hospital to home: An overview of systematic reviews and recommendations for improving transitional care in the Veterans Health Administration.

70. Kripalani, S., Jackson, A. T., Schnipper, J. L., \& Coleman, E. A. (2007). Promoting effective transitions of care at hospital discharge: a review of key issues for hospitalists. Journal of hospital medicine: an official publication of the Society of Hospital Medicine, 2(5), 314-323. doi: https://doi.org/10.1002/jhm.228

71. Kunkel, S., Rosenqvist, U., \& Westerling, R. (2007). The structure of quality systems is important to the process and outcome, an empirical study of 386 hospital departments in Sweden. BMC health services research, 7(1), 104. doi: https://doi.org/10.1186/1472-6963-7-104

72. Lin, C.-J., Cheng, S.-J., Shih, S.-C., Chu, C.-H., \& Tjung, J.-J. (2012). Discharge planning. International Journal of Gerontology, 6(4), $237-$ 240. doi: https://doi.org/10.1016/j.ijge.2013.01.011

73. Lingle, C. L. (2013). Evidence Based Practice: Patient Discharge Education Barriers to Patient Education.

74. Longmore, B., \& Ronnie, L. (2014). Human resource management practices in a medical complex in the Eastern Cape, South Africa: Assessing their impact on the retention of doctors. South African Medical Journal, 104(5), 368 - 371. doi: https://doi.org/10.7196/SAMJ.7751

75. Lukasiewicz, A. M., Grant, R. A., Basques, B. A., Webb, M. L., Samuel, A. M., \& Grauer, J. N. (2016). Patient factors associated with 30-day morbidity, mortality, and length of stay after surgery for subdural hematoma: a study of the American College of Surgeons National Surgical Quality Improvement Program. Journal of neurosurgery, 124(3), 760-766.

76. MacPhee, M., Dahinten, V. S., \& Havaei, F. (2017). The impact of heavy perceived nurse workloads on patient and nurse outcomes. Administrative Sciences, 7(1), 7.

77. Mesfin, E. A., Taye, B., Belay, G., Ashenafi, A., \& Girma, V. (2017). Factors affecting quality of laboratory services in public and private health facilities in Addis Ababa, Ethiopia. EJIFCC, 28(3), 205.

78. Mitchell, M., Chaboyer, W., Burmeister, E., \& Michelle, F., (2009). Positive Effects of a Nursing Intervention on Family-Centered Care in Adult Critical Care.

79. Mitchell, P. H., Ferketich, S., Jennings, B. M., \& Care, A. A. o. N. E. P. o. Q. H. (1998). Quality health outcomes model. Image: The Journal of Nursing Scholarship, 30(1), 43-46. 
80. Mohanan, K., Kaur, S., Das, K., \& Bhalla, A. (2010). Patient satisfaction regarding nursing care at Emergency Outpatient Department in a tertiary care hospital. Journal of Mental Health \& Human Behaviour, 15(1), 54-58.

81. Moore, L., Lavoie, A., Bourgeois, G., \& Lapointe, J. (2015). Donabedian's structure-process-outcome quality of care model: Validation in an integrated trauma system. Journal of Trauma and Acute Care Surgery, 78(6), 1168-1175.

82. Morris, J., Louise, W., \& Kim, Y. (2011). Registered nurses' perceptions of the discharge planning process for adult patients in an acute hospital. Journal of Nursing Education and Practice, 2(1), 28. doi: 10.5430/jnep.v2n1p28

83. Munjanja, O. K., Kibuka, S., \& Dovlo, D. (2005). The nursing workforce in sub-Saharan Africa: International council of nurses.

84. Nates, J. L., Nunnally, M., Kleinpell, R., Blosser, S., Goldner, J., Birriel, B., .. . Bailey, H. (2016). ICU admission, discharge, and triage guidelines: a framework to enhance clinical operations, development of institutional policies, and further research. Critical care medicine, 44(8), 1553-1602.

85. Nordmark, S., Zingmark, K., \& Lindberg, I. (2016). Process evaluation of discharge planning implementation in healthcare using normalization process theory. BMC medical informatics and decision making, 16(1), 48.

86. Nursing and Midwifery Council of Ghana. (2015). Standard Procedure Manual.

87. Osei-Ampofo, M., Oduro, G., Oteng, R., Zakariah, A., Jacquet, G., \& Donkor, P. (2013). The evolution and current state of emergency care in Ghana. African Journal of Emergency Medicine, 3(2), 52-58. doi: https://doi.org/10.1016/j.afjem.2012.11.006

88. Palonen, M., Kaunonen, M., Helminen, M., \& Astedt-Kurki, P. (2015). Discharge education for older people and family members in emergency department: A cross-sectional study. International emergency nursing, 23(4), 306-311.

89. Parasuraman, A., Zeithaml, V. A., \& Berry, L. L. (1985). A conceptual model of service quality and its implications for future research. the Journal of Marketing, 41-50.

90. Pines, J. M., \& Bernstein, S. L. (2015). Solving the worldwide emergency department crowding problem-what can we learn from an Israeli ED? Israel journal of health policy research, 4(1), 52.

91. Polit, D.F., Beck, C.T. (2008). Nursing research. Generating and assesing evidence for nursing practice (Eighth ed.). Philadelphia: Lippincott Williams \& Wilkins. 
92. Pompeo, D. A., Pinto, M. H., Cesarino, C. B., Araújo, R. R. D. F. d., \& Poletti, N. A. A. (2007). Nurses' performance on hospital discharge: patients' point of view. Acta Paulista de Enfermagem, 20(3), 345-350.

93. Preyde, M., Macaulay, C., \& Dingwall, T. (2009). Discharge planning from hospital to home for elderly patients: a meta-analysis. Journal of evidence-based social work, 6(2), 198-216.

94. Rajkumari, B., \& Nula, P. (2017). Patient's satisfaction with care in a government health facility in North East India: A cross-sectional study. Journal of Medical Society, 31(2), 94.

95. Rodrigues, A. V. D., Vituri, D. W., Haddad, M. d. C. L., Vannuchi, M. T. O., \& Oliveira, W. T. d. (2012). Nursing care responsiveness from the client's view. Revista da Escola de Enfermagem da USP, 46(6), 1446-1452.

96. Samuels-Kalow, M., Rhodes, K., Uspal, J., Reyes Smith, A., Hardy, E., \& Mollen, C. (2016). Unmet needs at the time of emergency department discharge. Academic Emergency Medicine, 23(3), 279287. doi: https://doi.org/10.1111/acem. 12877

97. Saunders, M., Lewis, P., \& Thornhill, A. (2009). Research methods for business students: Pearson education.

98. Schoen, C., Osborn, R., Squires, D., Doty, M., Pierson, R., \& Applebaum, S. (2011). New 2011 survey of patients with complex care needs in eleven countries finds that care is often poorly coordinated. Health Affairs, 30(12), 2437-2448.

99. Shepperd, S., Lannin, N. A., Clemson, L. M., McCluskey, A., Cameron, I. D., \& Barras, S. L. (2013). Discharge planning from hospital to home.

100. Shepperd, S., Lannin, N. A., Clemson, L. M., McCluskey, A., Cameron, I. D., \& Barras, S. L. (2016). Discharge planning from hospital to home. Cochrane database of systematic reviews(1).

101. Shepperd S, McClaran J, Phillips C., O., Lannin, N. A., Clemson, L. M., McCluskey, A., Cameron, I. D., \& Barras, S. L. (2010) Discharge planning from hospital to home. Cochrane Database Syst Rev.

102. Shinde, M., \& Kapurkar, K. (2014). Patient's satisfaction with nursing care provided in selected areas of tertiary care hospital. International Journal of Science and Research, 3(2), 150-161.

103. Snow, V., Beck, D., Budnitz, T., Miller, D. C., Potter, J., Wears, R. L., . . . Williams, M. V. (2009). Transitions of care consensus policy statement American college of physicians-society of general internal medicine-society of hospital medicine-American geriatrics society-American college of emergency physicians-society 
of academic emergency medicine. Journal of general internal medicine, 24(8), 971-976.

104. Sondaal, S. F. V., Browne, J. L., Amoakoh-Coleman, M., Borgstein, A., Miltenburg, A. S., Verwijs, M., \& Klipstein-Grobusch, K. (2016). Assessing the effect of mHealth interventions in improving maternal and neonatal care in low-and middle-income countries: a systematic review. PloS one, 11(5), e0154664.

105. Soong, C., Daub, S., Lee, J., Majewski, C., Musing, E., Nord, P., . . Bell, C. M. (2013). Development of a checklist of safe discharge practices for hospital patients. Journal of hospital medicine, 8(8), 444449. doi: https://doi.org/10.1002/jhm.2032

106. Sprivulis, P. C., Da Silva, J., Jacobs, I. G., Frazer, A. R., \& Jelinek, G. A. (2006). The association between hospital overcrowding and mortality among patients admitted via Western Australian emergency departments. Medical Journal of Australia, 184(5), 208212.

107. Stanley, A., Graham, N., \& Parrish, A. (2008). A review of internal medicine re-admissions in a peri-urban South African hospital. South African Medical Journal, 98(4), 291-294.

108. Subedi, D., \& Uprety, K. (2014). Patients Satisfaction with Hospital Services in Kathmandu. J Chitwan Med Coll, 4(9), 25.

109. Tsilimingras, D., Schnipper, J., Duke, A., Agens, J., Quintero, S., Bellamy, G., Bates, W. (2015). Post-Discharge Adverse Events Among Urban and Rural Patients of an Urban Community Hospital: A Prospective Cohort Study, 1164-1171. https://doi.org/10.1007/s11606-015-3260-3

110. Vance, J., \& Sprivulis, P. (2005). Triage nurses validly and reliably estimate emergency department patient complexity. Emergency Medicine Australasia, 17(4), 382-386.

111. Viccellio, A., Santora, C., Singer, A. J., Thode Jr, H. C., \& Henry, M. C. (2009). The association between transfer of emergency department boarders to inpatient hallways and mortality: a 4-year experience. Annals of emergency medicine, 54(4), 487-491.

112. Wallace, E., Smith, S. M., Fahey, T., \& Roland, M. (2016).

Reducing emergency admissions through community based interventions. BMJ, 352, h6817. doi: https://doi.org/10.1136/bmj.h6817

113. Waring, J., Marshall, F., Bishop, S., Sahota, O., Walker, M. F., Currie, G., . . . Avery, T. J. (2014). An ethnographic study of knowledge sharing across the boundaries between care processes, services and organisations: the contributions to 'safe'hospital discharge. Health Services and Delivery Research, 2(29), 1-160. 
114. Wells, D. L., LeClerc, C. M., Craig, D., Martin, D. K., \& Marshall, V. W. (2016). Evaluation of an integrated model of discharge planning: achieving quality discharges efficiently and ethically. Canadian Journal of Nursing Research Archive, 34(3).

115. White, B. A., Biddinger, P. D., Chang, Y., Grabowski, B., Carignan, S., \& Brown, D. F. (2013). Boarding inpatients in the emergency department increases discharged patient length of stay. The Journal of emergency medicine, 44(1), 230-235.

116. Wolf, L., Brysiewicz, P., Lobue, N., Heyns, T., Bell, S. A., Coetzee, I., ... Hangula, R. (2012). Developing a framework for emergency nursing practice in Africa. African Journal of Emergency Medicine. https://doi.org/10.1016/j.afjem.2012.09.001

117. Wong, E. L., Cheung, A. W., Leung, M. C., Yam, C. H., Chan, F. W., Wong, F. Y., \& Yeoh, E.-K. (2011). Unplanned readmission rates, length of hospital stay, mortality, and medical costs of ten common medical conditions: a retrospective analysis of Hong Kong hospital data. BMC health services research, 11(1), 149.

118. Yamane, T. (1967). Elementary sampling theory. 